Revista de
Economia
Contemporâned

\title{
CARACTERÍSTICAS E SIMILARIDADES DO SETOR CULTURAL NOS MUNICÍPIOS E REGIÕES METROPOLITANAS BRASILEIRAS*
}

\author{
Luiz Carlos de Santana Ribeiro ${ }^{a}$ \\ Thiago Henrique Carneiro Rios Lopes ${ }^{b}$ \\ aDepartamento de Economia da Universidade Federal de Sergipe.

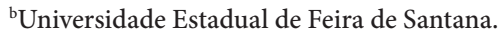

Artigo recebido em 11/12/2013 e aceito em 25/08/2015.

\begin{abstract}
RESUMO: A promoção de políticas regionais que visam a desenvolver um determinado setor exige, num primeiro momento, sua caracterização e descrição do ponto de vista regional. Dessa forma, este artigo contribui no sentido de oferecer uma classificação dos 5.570 municípios brasileiros sob a ótica formal do mercado de arte e cultura. Para tanto, duas metodologias complementares foram desenvolvidas, quais sejam: i) análise de conglomerados; e ii) método diferencial-estrutural modificado. Acredita-se que a partir dessa caracterização, estudos posteriores possam ser desenvolvidos no sentido de propor políticas regionais que fortaleçam o setor de arte e cultura.
\end{abstract}

PALAVRAS-CHAVE: setor cultural; cluster; shift-share; municípios brasileiros.

CLASSIFICAÇÃO JEL: C38; R15; Z11.

Os autores agradecem à professora Ana Flávia Machado pelos comentários e sugestões, os quais contribuíram diretamente para a elaboração deste estudo. No entanto, o texto é de inteira responsabilidade dos autores.

Correspondência para: Luiz Carlos de Santana Ribeiro.

Contato: ribeiro.luiz84@gmail.com. 


\title{
CHARACTERISTICS AND SIMILARITIES OF CULTURAL INDUSTRIES IN BRAZILIAN CITIES AND METROPOLITAN REGIONS
}

\begin{abstract}
The promotion of regional policies aimed at developing a particular industry requires, at first, a characterization and description from a regional point of view. Thus, this paper contributes towards offering a classification of the formal market of art and culture in the 5,570 Brazilian municipalities. For this, two complementary methodologies have been applied, namely: i) cluster analysis, and ii) shift-share analysis. It is believed that, based on this characterization, further studies can be developed to propose regional policies that strengthen the art and culture industries.
\end{abstract}

KEYWORDS: cultural industries; cluster; shift-share; Brazilian municipalities. 


\section{INTRODUÇÃO}

Durante muito tempo, a arte e a cultura foram tratadas apenas de forma superficial pela maioria dos economistas. Os autores clássicos, por exemplo, estavam preocupados, especialmente, com a escassez e a produção de riqueza. O contato que eles tiveram com a arte se limitava ao luxo esbanjado pela aristocracia local e, portanto, tais autores não a viam como um elemento relevante para a expansão do produto nacional. Todavia, o mercado cultural ${ }^{1}$ se desenvolveu e passou a ganhar espaço inclusive no meio acadêmico. Markusen (2007), baseada na ótica do consumo, demonstra que os investimentos culturais podem promover crescimento e desenvolvimento econômico.

Os economistas passaram a perceber que a arte e a cultura atraem visitantes que despendem seu dinheiro na localidade. No entanto, eles não irão gastar recursos apenas com as artes propriamente ditas, mas também com alimentação, alojamento, bebidas etc. Esse aumento de demanda agregada na região pode, em parte, ser atribuída ao evento artístico que motivou a visita dos turistas. Neste caso, tal evento pode gerar: i) efeitos diretos - que são os empregos e a renda gerados na localidade devido às atividades artísticas; ii) efeitos induzidos - que são medidos pelos gastos dos visitantes em alimentos, bebidas, acomodação etc.; e iii) efeitos indiretos - que são os efeitos multiplicadores. Note, portanto, que a geração de riqueza de uma região pode ser expandida pelo mercado cultural.

Admitindo-se que os setores de arte e cultura podem representar importantes parcelas do produto regional/nacional, alguns autores aplicaram uma série de métodos tentando mensurar os impactos deste setor em distintas localidades. Markusen e Schrock (2005), por exemplo, afirmam que a contribuição econômica regional das artes é geralmente medida pela soma das receitas das grandes organizações artísticas, despesas associadas por patronos e efeitos multiplicadores. Contudo, este método, segundo eles, subestima a contribuição dos artistas criativos para a economia regional, devido, em parte, às altas taxas de empregos informais e de atividade de exportação direta. Christoffersen e Lyk-Jensen (1994), por sua vez, por meio de um modelo de insumo-produto, mostraram a importância do turismo cultural de uma instituição de arte dinamarquesa, a Brandts Klaedefabrik, para a economia local2. Utilizando a

1 Vale salientar que o tamanho deste mercado tem sido mensurado em alguns países desenvolvidos: Dinamarca, 5,3\% do PIB; Grã-Bretanha, 8\%; Suécia, 9\%; EUA, 7,8\%; Noruega, 3,5\%; e Nova Zelândia, 3,1\% (Haraldsen et al. apud Bille et al., 2006).

2 Os autores compararam o impacto econômico desta instituição com formas alternativas de uso de recursos, quais sejam: i) efeitos de uma expansão geral de atividades públicas; e ii) efeitos de outro estabelecimento cultural, a casa de Hans Christian Andersen (Bille et al., 2006). 
mesma modelagem, Scanlon e Longley (1984) estimaram o impacto econômico da cultura sobre a área metropolitana de Nova York - Nova Jersey. As artes, segundo esses autores, tiveram um impacto de U\$ 5,6 bilhões na região. Além disso, elas foram a principal indústria de exportação desta região no período estudado. Autores como Diniz e Machado (2011) e Paglioto e Machado (2012) utilizaram abordagens econométricas para avaliar, respectivamente, o consumo de bens e serviços culturais e o perfil dos consumidores deste mercado.

Um dos maiores desafios em nível local, segundo Markusen (2006), é a fragmentação das responsabilidades em relação às políticas culturais e artísticas. Para esta autora, nas cidades menores é mais fácil juntar forças com potenciais parceiros para desenvolver uma vida econômica e cultural vibrante. $\mathrm{O}$ estabelecimento de parcerias e a clara atribuição de responsabilidade são fundamentais para o desenvolvimento dessas atividades, pois, tal como acontece com centros de convenções, estádios e prisões, determinados equipamentos culturais podem gerar consequências negativas para o erário público no longo prazo. Ademais, o setor público pode incentivar a comunicação e planejamento conjunto entre os setores culturais, utilizando suas ferramentas e recursos de regulação para esse fim. Para Markusen e Schrock (2005), as cidades podem estimular os trabalhos artísticos de muitas formas. Uma delas é por meio do apoio dos centros de artistas - que são lugares em que eles se reúnem para compartilhar seus ofícios e aprender formas de viver a vida por meio da arte. Os autores ainda defendem que o estado deve melhorar seus critérios de alocação de recursos públicos para as artes.

Diante do exposto, nota-se que vários autores têm se preocupado em estudar como as artes e a cultura podem contribuir para o desenvolvimento regional. Entende-se, aqui, que a formulação de políticas regionais que busquem desenvolver este setor requer, como primeiro passo, uma caracterização espacial dessas atividades. No Brasil, o aumento progressivo do nível de renda da população associado às políticas de incentivo à cultura tem elevado a demanda por serviços culturais.

A partir disso, este trabalho tenta identificar algumas características dos municípios e regiões metropolitanas brasileiras do ponto de vista das atividades artísticas e culturais. Portanto, o objetivo deste artigo é, num primeiro momento, identificar eventuais grupos de municípios brasileiros a partir de semelhanças entre seus setores culturais e, posteriormente, avaliar quais regiões metropolitanas apresentam características de competitividade, especialização e dinamismo. Para isso, aplicaremos a análise de conglomerados (cluster) e o método diferencial-estrutural (shift-share). Em outras palavras, a ideia é utilizar esses métodos de forma complementar e tentar identificar padrões estruturais que auxiliem o desenvolvimento de futuras políticas.

Para a apresentação desta proposta, o artigo está dividido em quatro seções, além desta introdução e das considerações finais. A primeira revisa a literatura sobre econo- 
mia da cultura, enfatizando sua relação com o desenvolvimento e o espaço. A segunda apresenta a metodologia de análise de conglomerados e do shift-share. A terceira seção descreve a base de dados e o tratamento das variáveis. A quarta seção apresenta e discute os resultados. Por fim, são apresentadas as considerações finais.

\section{CULTURA, DESENVOLVIMENTO E ESPAÇO}

Desde meados dos anos 1990, quando o termo "cidade criativa" ganhou espaço, planejadores urbanos passaram a ver nas artes e nas atividades culturais uma alternativa para revitalizar os centros urbanos, bem como atrair turistas, preservar construções históricas e resolver alguns problemas da comunidade. Os esforços para o desenvolvimento da economia criativa favorecem a atração de novos artistas, bem como a manutenção, na localidade, daqueles que ali já trabalham. A ideia de que as atividades relacionadas à arte e à cultura podem servir como uma estratégia de desenvolvimento ocorre porque esse dividendo cultural é uma função tanto de deslocar gastos locais das importações quanto de elevados multiplicadores locais associados com os gastos culturais, uma vez que este segmento é de trabalho intensivo e os beneficiários dos rendimentos culturais são mais propensos em gastá-los localmente (Markusen, 2006). A preferência dos indivíduos pelo gasto local em detrimento do consumo de bens importados ou em viagens é intensificada quando ocorre o fornecimento de melhores oportunidades culturais naquela localidade (Markusen, 2007).

Nesse contexto, a cultura e as artes, segundo Bille et al. (2006), poderiam promover o desenvolvimento urbano e regional, em curto prazo, ao aumentar a demanda global por serviços e bens regionais. Por outro lado, elas podem estimular o desenvolvimento em longo prazo por meio do aumento da atratividade de uma região por firmas, pessoas e atividades econômicas em geral. De acordo com esses autores, muitas pessoas podem concordar com a ideia de que as artes são importantes na formação de fatores para o desenvolvimento, tais como: de identidade, personalidade, atitude, motivação, criatividade etc. Ademais, a atividade artística e cultural pode levar indiretamente a um desenvolvimento industrial mais inovativo.

Kotkin (2000), Sommers e Carlson (2000) e Florida (2002) argumentam que uma atmosfera cultural pujante favorece a atração de firmas, pois elas podem encontrar pessoas mais criativas nesses ambientes. Florida (2002) sugere que tolerância, talento e tecnologia são elementos que guiam o processo de crescimento econômico. Associada a isso, a indústria cultural tem ganhado atenção porque tem se mostrado crescente em vários países do mundo. A expansão é resultante da demanda crescente por experiências, cultura, eventos e atividades de lazer (Bille et al., 2006). Na mesma direção, 
Markusen e Schrock (2005) apresentam uma visão centrada na economia das artes, sob a hipótese de que muitos artistas escolhem uma localidade para trabalhar sem considerar seus possíveis empregadores, mas em resposta a um apreço pela arte, conforto e custo de vida.

Scott (2004) sugere que os aspectos econômicos e culturais devem ser incorporados aos estudos de desenvolvimento regional. Isso acontece, em grande medida, porque a distribuição espacial do capital humano, bem como a dos indivíduos criativos, pode ajudar na compreensão tanto do desenvolvimento quanto das diversidades regionais. Jacobs (2001), por exemplo, já havia alertado que as cidades são peças centrais na atração de pessoas criativas. $\mathrm{O}$ argumento, portanto, é que cidades ou regiões que têm relativa aglomeração de pessoas criativas obterão ganhos de produtividade, decorrentes deste processo, que será maior vis-à-vis aos locais com baixa concentração deste perfil populacional. Os ganhos de produtividade, por conseguinte, explicam parte do desenvolvimento regional.

Embora os ganhos de produtividade sejam um dos principais elementos que explicam a relação desenvolvimento x economia criativa, existem outros mecanismos por meio dos quais isso pode ser notado: amenidades dadas pelo ambiente urbano, interação da classe criativa com o capital social e capital humano, por exemplo. Além do mais, Waitt e Gibson (2009) apontam que a economia criativa pode ajudar na regeneração de grandes centros urbanos, bem como dar algumas dinâmicas às pequenas cidades que consigam atrair pessoas criativas.

Contudo, a atração dessas pessoas não depende exclusivamente de fatores econômicos, tais como salário, custo de vida e qualidade dos empregos. Questões extraeconômicas, como oportunidades de lazer, baixa criminalidade e trânsito menos congestionado podem servir para atrair aqueles que já possuem algum nível de escolaridade e qualificação. Ademais, parece razoável imaginar, tal como exposto por Flórida (2002), que haverá maior probabilidade de atração de pessoas criativas se determinada cidade possuir um grande contingente de indivíduos atuando em atividades ligadas ao entretenimento.

Tendo em vista que as questões associadas à cultura podem influenciar positivamente o processo de desenvolvimento regional, pois elas atraem indivíduos criativos e mais produtivos, alguns trabalhos tentaram mapear a localização e a concentração dessas atividades no Brasil. Utilizando dados das Pesquisas Nacionais de Amostras por Domicílios (PNAD) de 1986, 1992, 1998 e 2004, Golgher (2008) procurou observar a distribuição de trabalhadores qualificados e sua ocupação nas atividades criativas brasileiras. Há, segundo o autor, uma clara heterogeneidade entre os estados brasileiros do ponto de vista da concentração de trabalhadores criativos, cuja concentração é mais baixa nos estados do Norte e Nordeste. A partir das análises de regressões múltiplas, 
ele percebeu que as maiores proporções de trabalhadores na economia criativa estavam localizadas em municípios: i) com populações maiores; ii) mais urbanizados; iii) localizados nas regiões Sul/Sudeste/Centro-Oeste; e iv) com maior índice de entretenimento.

Visando a estudar o consumo dos bens e serviços culturais nas metrópoles brasileiras, Diniz e Machado (2009) afirmam, utilizando dados da Pesquisa de Orçamento Familiar (POF) 2002-2003, que apenas cerca de 26\% dos domicílios pesquisados apresentaram algum gasto em bens e serviços culturais. Além disso, o maior gasto reside nos domicílios urbanos, sendo mais forte nas capitais. Também foi possível notar que o valor do gasto cresce com a renda, mas especialmente que um incremento na renda dos domicílios que já contam com níveis de renda elevados implica aumento mais que proporcional nos gastos em cultura.

Machado et al. (2013) descrevem o potencial criativo dos territórios brasileiros. Isso inclui aspectos pontuados como vantagens comparativas das cidades em termos de criatividade. Os autores tentam, especificamente, identificar quais elementos podem contribuir para transformar aglomerações produtivas em clusters criativos. A partir da utilização de 35 variáveis, obtidas de várias fontes, eles conseguiram identificar seis clusters. O primeiro é composto por apenas duas cidades: Rio de Janeiro e São Paulo; que são as maiores cidades do Brasil e possuem muitas indústrias criativas, tais como a de audiovisual e a de publicidade. O segundo cluster é formado por 18 cidades, cujas características se assemelham às do primeiro, mas com uma taxa de homicídios superior. O terceiro grupo, formado por 99 municípios, é marcado por elevado gasto em cultura per capita. Os agrupamentos 4, 5 e 6 são difusos e têm uma distribuição espacial dispersa.

A concentração de pessoas criativas em determinado centro urbano contribuirá para que ele tenha uma densidade maior de indivíduos qualificados. Por conseguinte, o padrão de crescimento nesses ambientes deverá ser mais dinâmico. Golgher (2011) elabora um indicador de entretenimento como proxy de uma sociedade vibrante, que favorece a atração de indivíduos criativos, qualificados, e, portanto, mais produtivos. O índice trata-se da proporção dos trabalhadores das artes e de profissionais de espetáculos. Em 2000, as regiões metropolitanas com maior índice de entretenimento foram: Rio de Janeiro, Salvador, Baixada Santista, Natal e Fortaleza. Um dos resultados obtidos foi que regiões com maiores índices de entretenimento tendem a ter maiores níveis de qualificação. Por fim, por meio da técnica de aglomerados, o autor classifica as 24 regiões metropolitanas em cinco grupos.

Ribeiro et al. (2014) tentaram verificar o padrão de distribuição espacial da indústria do lazer nos municípios brasileiros e associá-los com um indicador de desenvolvimento. Os autores utilizaram nove variáveis para a elaboração dos clusters. O primeiro 
foi formado por apenas duas cidades: Rio de Janeiro e São Paulo, onde a indústria do lazer mostrou-se mais especializada e concentrada. O segundo agrupamento foi composto por 672 cidades com semelhantes características, sendo 22 capitais; aqui, a concentração espacial da indústria do lazer foi menor quando comparada à do primeiro agrupamento. $\mathrm{O}$ terceiro grupo teve 401 municípios cuja principal característica foi a maior despesa per capita em esporte e lazer em relação aos demais. O quarto grupo, com 34 cidades, é caracterizado por uma indústria de lazer não especializada e não concentrada. Por fim, o último cluster é formado por 4.456 municípios com indicadores abaixo da média nacional; nesses locais a indústria do lazer é, no mínimo, incipiente, segundo os autores.

Nota-se, portanto, que diversos estudos tentaram mapear a concentração e/ou distribuição espacial do setor cultural no Brasil. O referido trabalho, ao utilizar um conjunto mais restrito de variáveis, as quais consideram apenas os aspectos formais do setor cultural, busca investigar, dentre outras coisas, se o padrão de distribuição permanece tal como sugerido pelos trabalhos anteriores. Isto é, alta concentração e poucos municípios formando a maioria dos clusters, além da ampla maioria das cidades brasileiras formando apenas um grupo marcado pelo baixo dinamismo da atividade cultural.

\section{METODOLOGIA}

\subsection{ANÁLISE DE CONGLOMERADOS (CLUSTERS)}

Para classificar os municípios brasileiros do ponto de vista das características associadas às atividades culturais, optou-se pela realização da análise de clusters. Este método permite reunir casos ou variáveis em grupos homogêneos. A ideia é segmentar as observações em grupos com características similares entre si e diferentes entre os demais.

Entretanto, do ponto de vista teórico, o surgimento de um distrito cultural está baseado na junção de dois fenômenos: o da localização, identificado primeiro por Marshall (1984), e o da peculiar ou idiossincrática natureza da cultura. Quando esses dois fatores essenciais são reunidos em um ambiente econômico receptivo, as condições básicas para um potencial distrito cultural são atendidas (Santagata, 2006).

Tendo em vista que a análise de cluster visa a agrupar objetos semelhantes, é necessária a utilização de alguma medida da distância entre eles. Dessa forma, objetos mais próximos entre si são mais semelhantes e, portanto, farão parte do mesmo agrupamento. Segundo Hair et al. (2005), a similaridade entre os objetos pode ser medida das seguintes maneiras: a) medidas correlacionais; b) medidas de distância; e c) medidas de associação. De acordo com esses autores, as medidas de distância são mais frequen- 
temente usadas. Este trabalho utilizou a medida da Distância Quadrática Euclidiana, cuja aproximação é realizada da seguinte forma: a distância entre as observações ( $i$ e $j$ ) é dada pela soma dos quadrados das diferenças entre $i$ e $j$ para todas as $p$ variáveis:

$$
d_{i j}^{2}=\sum_{k=1}^{p}\left(x_{i k}-x_{j k}\right)^{2}
$$

Em (1):

$x_{i k}$ é o valor da variável $k$ associada à observação $i$; e

$x_{j k}$ é o valor da variável $k$ para a observação $j$.

Este trabalho utilizou os dois principais métodos básicos de agrupamento: o hierárquico e o não hierárquico. No método hierárquico é preciso definir como computar a distância entre o cluster mais próximo, para, posteriormente, escolher a forma como computar as distâncias entre os grupos já formados. Para tanto, Fávero et al. (2009) indicam como métodos mais utilizados o Single Linkage, Complete Linkage, Average Linkage, Centroid e Ward. Seguindo a orientação de Hair et al. (2005), o método Ward foi utilizado, pois, segundo esses autores, é o mais adequado quando se faz uso da distância quadrática euclidiana.

\subsection{MÉTODO DIFERENCIAL-ESTRUTURAL}

O método diferencial-estrutural busca descrever o crescimento econômico de uma região a partir da sua estrutura produtiva. Não se deve confundi-lo, contudo, com uma teoria que explique o crescimento regional, mas sim com uma técnica de análise que nos permitirá identificar os componentes desse crescimento. Assim, por meio de um conjunto de identidades contábeis, o método indica que o crescimento de uma determinada região é consequência de dois fatores: 1) sua estrutura produtiva ser constituída, majoritariamente, por setores mais dinâmicos; ou 2) apresentar participação crescente na distribuição regional do emprego. Desse modo, o crescimento regional é decomposto numa variação estrutural e numa variação diferencial (Haddad, 1989).

No entanto, Esteban-Marquillas (1972) propôs uma modificação deste método a partir da incorporação dos efeitos alocação e competitivo. Segundo o autor, o objetivo dessa reformulação é eliminar a influência estrutural resultante da distribuição setorial do emprego do ano inicial para o cálculo do efeito diferencial. Desse modo, podemos formalizar o modelo considerando que o ano inicial (2006) será representado por 0 e o ano final (2013) corresponderá a 1. Os componentes do crescimento regional serão definidos como: variação regional $(\mathrm{R})$, variação estrutural (E), variação diferencial (D), efeito competitivo (C) e efeito de alocação (A), ou seja: 


$$
\begin{aligned}
& \underbrace{\sum_{i} E_{i j}{ }^{1}-\sum_{i} E_{i j}{ }^{0}}_{V T}= \\
& \underbrace{\sum_{i} E_{i j}^{0}\left(r_{t t}-1\right)}_{R}+\underbrace{\sum_{i} E_{i j}^{0}\left(r_{i t}-r_{t t}\right)}_{E}+\underbrace{\sum_{i} E_{i j}^{0}\left(r_{i j}-r_{i t}\right)}_{C} \\
& +\underbrace{\sum_{i}\left[\left(E_{i j}^{0}-E^{00}{ }_{i j}\right)\left(r_{i j}-r_{i i}\right)\right]}_{A}
\end{aligned}
$$

Em (2), VT representa a variação total de emprego entre o período final e o inicial na região $j$. Dessa forma, a variação líquida total (VLT) é dada por:

$$
V L T=V T-R=E+C+A
$$

Em (3), $R$ representa acréscimo de emprego se a região $j$ tivesse a taxa de crescimento do emprego de todas as regiões;

$r_{t t}=\left(\sum_{i} \sum_{j} E_{i j}^{1}\right) / \sum_{i} \sum_{j} E_{i j}^{0}$ é o crescimento do emprego de todas as regiões;

$r_{i t}=\sum_{j} E_{i j}^{1} / \sum_{j} E_{i j}^{0}$ é a taxa de crescimento do emprego no setor $i$ em todas as regiões;

$r_{i j}=E_{i j}^{1} / E^{0}{ }_{i j}$ é a taxa de crescimento do emprego do setor $i$ da região $j$; e

$E_{i j}^{\prime}=\sum_{i} E_{i j}\left(\sum_{j} E_{i j} / \sum_{i} \sum_{j} E_{i j}\right)$ é o emprego homotético, isto é, emprego no setor $i$ se a região $j$ tivesse a mesma estrutura de emprego do total das regiões.

A partir da definição do efeito alocação proposto por Esteban-Marquillas (1972), podemos construir a Tabela 1, que expressa as classificações possíveis por meio do resultado deste efeito.

Tabela 1 - Resultados do efeito alocação

\begin{tabular}{llccc}
\hline & \multirow{2}{*}{ Alternativas } & Efeito Alocação & \multicolumn{2}{c}{ Componentes } \\
\cline { 3 - 5 } & & & Especialização & Vantagem Competitiva \\
\hline I & Vantagem Competitiva Especializada & + & + & + \\
II & Vantagem Competitiva Não Especializada & - & - & + \\
III & Desvantagem Competitiva Não Especializada & + & - & - \\
IV & Desvantagem Competitiva Especializada & - & + & - \\
\hline
\end{tabular}




\section{BASE DE DADOS E TRATAMENTO DAS VARIÁVEIS}

$\mathrm{Na}$ análise de cluster, para classificar os municípios do ponto de vista das características associadas às atividades culturais, utilizaram-se as seguintes variáveis: 1) número de estabelecimentos relacionados às atividades culturais por cada 10.000 habitantes; 2) número de empregos formais nas atividades culturais em proporção do número de emprego total; e 3) renda média obtida nos setores culturais em proporção ao rendimento médio dos trabalhadores. Esses dados são referentes ao ano de 2013 e foram obtidos na Relação Anual de Informações Sociais (RAIS). É fundamental destacar que essas informações correspondem apenas às atividades formais e, por esse motivo, há uma série de limitações decorrentes do uso desse banco de dados.

A escolha dos municípios como unidade espacial justifica-se pelo fato de que a cultura possui dinâmicas locais. Ademais, isso se enquadra nas sugestões de Forman (1984), quando este afirma que, na análise de cluster, o número de casos ( $n$ ) deve ser igual a $5 \times 2^{k}$, em que $k$ é o número de variáveis a serem utilizadas na análise. Como foram utilizadas três variáveis, indicadas anteriormente, deve-se considerar no mínimo 40 casos (unidades espaciais). Portanto, o uso dos municípios é mais que suficiente para a realização do presente estudo.

Para a aplicação do shift-share, a base de dados para o estudo do setor cultural/ criativo das 38 Regiões Metropolitanas (RME) brasileiras corresponde ao número de empregos formais por atividades econômicas de 2006 e 2013 da RAIS. O período escolhido para análise compreende os dados mais recentes disponíveis, além do fato de que o intervalo de sete anos é considerado razoável para a realização do estudo proposto. A escolha dessa base de dados se justifica devido ao nível de detalhamento geográfico e setorial dos dados que o sistema oferece ao pesquisador. Por outro lado, sua limitação é pautada na desconsideração dos empregos informais e da contabilização apenas dos estabelecimentos com mais de cinco empregados registrados.

A utilização de dados municipais da RAIS para a análise de shift-share é inviável, pois vários municípios brasileiros tiveram zero empregados no setor cultural no ano base (2006) ou no ano final (2013) do período em análise. Isto, por sua vez, inviabilizaria a decomposição proposta pelo método. Por esse motivo, utilizaram-se os dados de emprego referentes às 38 RME brasileiras. Somado a isso, segundo Golgher (2011), existe uma dinâmica intraurbana de pendulariedade dos residentes qualificados entre as diferentes cidades de uma mesma RME, o que gera um transbordamento entre os seus municípios.

Para a construção do banco de dados foi adotado o nível setorial "Classe" do Código Nacional de Atividades Econômicas 2.0 (CNAE 2.0), o qual oferece uma maior desagregação das atividades. No que remete à identificação das atividades culturais/ 
criativas, utilizaram-se conjuntamente as classificações da UNESCO e do Ministério da Cultura. De acordo com a primeira classificação, existem seis núcleos de setores criativos, a saber: 1) patrimônio natural e cultural; 2) espetáculos e celebrações; 3) artes visuais e artesanato; 4) livros e periódicos; 5) design e serviços criativos; e 6) audiovisual e mídias interativas. Além desses, existem os setores criativos relacionados: turismo (roteiro de viagens e serviços turísticos; serviços de hospitalidade), esportes e lazer (esportes; preparação física e bem-estar; parques temáticos e de diversão) e patrimônio imaterial (expressões e tradições orais, rituais, línguas e práticas sociais).

O Ministério da Cultura, por sua vez, considera que os setores criativos seguem quatro classificações ou escopos, os quais são listados na Tabela 2. Percebe-se que os setores criativos, embora sejam classificados de forma diferente pelas duas instituições citadas anteriormente, são basicamente os mesmos.

Tabela 2 - Escopo dos setores criativos

\begin{tabular}{ll}
\hline \multirow{2}{*}{ Patrimônio } & Patrimônio Material \\
& Patrimônio Imaterial \\
& Arquivos \\
& Museus \\
\hline \multirow{2}{*}{ Expressões Culturais } & Artesanato \\
& Culturas Populares \\
& Culturas Indígenas \\
& Culturas Afro-brasileiras \\
Artes de Espetáculo & Artes Visuais \\
& Dança \\
\hline & Música \\
Audivisual e do Livro, da Leitura e da literatura & Circo \\
& Teatro \\
\hline
\end{tabular}

Fonte: Ministério da Cultura (2011).

A partir do confronto das classificações da UNESCO e do Ministério da Cultura, considera-se, aqui, que o setor cultural é constituído por 23 atividades econômicas, as quais são listadas na Tabela 3.

Desse modo, para a aplicação dos métodos serão considerados seis grandes setores econômicos, a saber: agropecuária, indústria, construção civil, comércio, serviços culturais e serviços não culturais. Dados os objetivos do presente artigo, os resultados serão reportados somente para os serviços culturais. 
Tabela 3 - Serviços culturais/criativas

\begin{tabular}{ll}
\hline Código & CNAE 2.0 Classe \\
\hline 58115 & Edição de livros \\
58123 & Edição de jornais \\
58131 & Edição de revistas \\
58191 & Edição de cadastros, listas e de outros produtos gráficos \\
58212 & Edição integrada à impressão de livros \\
58221 & Edição integrada à impressão de jornais \\
58239 & Edição integrada à impressão de revistas \\
58298 & Edição integrada à impressão de cadastros, listas e de outros produtos gráficos \\
59111 & Atividades de produção cinematográfica, de vídeos e de programas de televisão \\
59120 & Atividades de pós-produção cinematográfica, de vídeos e de programas de televisão \\
59138 & Distribuição cinematográfica, de vídeo e de programas de televisão \\
59146 & Atividades de exibição cinematográfica \\
59201 & Atividades de gravação de som e de edição de música \\
60101 & Atividades de radio \\
60217 & Atividades de televisão aberta \\
60225 & Programadoras e atividades relacionadas à televisão por assinatura \\
85929 & Ensino de arte e cultura \\
90019 & Artes cênicas, espetáculos e atividades complementares \\
90027 & Criação artística \\
90035 & Gestão de espaços para artes cênicas, espetáculos e outras atividades artísticas \\
91015 & Atividades de bibliotecas e arquivos \\
91023 & Atividades de museus e de exploração, restauração artística e conservação de lugares e prédios históricos \\
94936 & e atraçães similares \\
\hline
\end{tabular}

Fonte: Elaboração própria a partir dos dados da RAIS.

\section{RESULTADOS E DISCUSSÕES}

Para a elaboração dos grupos, utilizou-se, num primeiro momento, o método hierárquico. Seguiu-se, assim, a orientação de Maroco (2007), quando ele sugere realizar o método não hierárquico apenas depois de considerar o número de clusters sugerido naquele primeiro momento. O método K-Means de aglomeração é o mais utilizado nos procedimentos não hierárquicos. Gouvêa e La Plata (2006) apontam que ele consegue minimizar a variância interna aos grupos, e, ao mesmo tempo, maximizar a variância entre os grupos. A distância Euclidiana, medida usada nesse procedimento, é definida como:

$$
d_{i j}=\sqrt{\sum_{k=1}^{p}\left(x_{i k}-x_{j k}\right)^{2}}
$$

Isso posto, os resultados dos clusters são apresentados por meio da Tabela 4 e da Figura 1. 
Tabela 4 - Resultado dos clusters dos serviços culturais

\begin{tabular}{|c|c|c|c|c|c|c|}
\hline Variável & Cluster & $\begin{array}{l}\text { Número de } \\
\text { municípios }\end{array}$ & Média & $\begin{array}{l}\text { Desvio } \\
\text { Padrão }\end{array}$ & $\begin{array}{c}\text { Valor } \\
\text { Mínimo }\end{array}$ & $\begin{array}{c}\text { Valor } \\
\text { Máximo }\end{array}$ \\
\hline \multirow{7}{*}{$\begin{array}{l}\text { Número de empregados } \\
\text { no setor cultural }\end{array}$} & 1 & 5.454 & 11,93 & 113,22 & 0 & 7.887 \\
\hline & 2 & 75 & 466,88 & 377,23 & 0 & 3.204 \\
\hline & 3 & 31 & 1652,97 & 811,13 & 526 & 3.772 \\
\hline & 4 & 8 & $5.690,88$ & $2.989,24$ & 16 & 9.515 \\
\hline & 5 & 1 & 31.582 & . & 31.582 & 31.582 \\
\hline & 6 & 1 & 51.828 & . & 51.828 & 51.828 \\
\hline & Total & 5.570 & 50,33 & 867,87 & 0 & 51.828 \\
\hline \multirow{7}{*}{$\begin{array}{l}\text { Número de } \\
\text { estabelecimentos do setor } \\
\text { cultural }\end{array}$} & 1 & 5.454 & 1,62 & 3,74 & 0 & 28 \\
\hline & 2 & 75 & 42,84 & 10,15 & 29 & 65 \\
\hline & 3 & 31 & 112,58 & 32,75 & 77 & 208 \\
\hline & 4 & 8 & 444,38 & 108,09 & 305 & 612 \\
\hline & 5 & 1 & 1.842 & . & 1842 & 1.842 \\
\hline & 6 & 1 & 3.141 & . & 3141 & 3.141 \\
\hline & Total & 5.570 & 4,32 & 52,73 & 0 & 3.141 \\
\hline \multirow{7}{*}{$\begin{array}{l}\text { Número de } \\
\text { estabelecimentos de } \\
\text { cultura para cada } 10.000 \\
\text { habitantes }\end{array}$} & 1 & 5.454 & 0,51 & 0,95 & 0,00 & 11,23 \\
\hline & 2 & 75 & 1,89 & 0,79 & 0,45 & 3,88 \\
\hline & 3 & 31 & 1,85 & 0,83 & 0,64 & 3,75 \\
\hline & 4 & 8 & 2,20 & 0,67 & 1,34 & 3,37 \\
\hline & 5 & 1 & 2,86 & . & 2,86 & 2,86 \\
\hline & 6 & 1 & 2,66 & . & 2,66 & 2,66 \\
\hline & Total & 5.570 & 0,54 & 0,96 & 0,00 & 11,23 \\
\hline \multirow{7}{*}{$\begin{array}{l}\text { Renda média do } \\
\text { trabalhador da cultura em } \\
\text { proporção à renda média } \\
\text { dos trabalhadores em } \\
\text { geral }\end{array}$} & 1 & 5454 & 0,03 & 0,07 & 0,00 & 1,1 \\
\hline & 2 & 75 & 0,46 & 0,12 & 0,16 & 0,73 \\
\hline & 3 & 31 & 0,58 & 0,11 & 0,41 & 0,86 \\
\hline & 4 & 8 & 0,73 & 0,06 & 0,65 & 0,83 \\
\hline & 5 & 1 & 1,21 & . & 1,21 & 1,21 \\
\hline & 6 & 1 & 1,48 & . & 1,48 & 1,48 \\
\hline & Total & 5.570 & 0,04 & 0,10 & 0,00 & 1,48 \\
\hline \multirow{7}{*}{$\begin{array}{l}\text { Empregados do setor de } \\
\text { cultura em proporção ao } \\
\text { número total de empregos }\end{array}$} & 1 & 5.454 & 0,0010 & 0,0037 & 0,000 & 0,06 \\
\hline & 2 & 75 & 0,0059 & 0,0052 & 0,000 & 0,02 \\
\hline & 3 & 31 & 0,0074 & 0,0044 & 0,000 & 0,01 \\
\hline & 4 & 8 & 0,0125 & 0,0071 & 0,010 & 0,03 \\
\hline & 5 & 1 & 0,0100 & . & 0,010 & 0,01 \\
\hline & 6 & 1 & 0,0100 & . & 0,010 & 0,01 \\
\hline & Total & 5.570 & 0,0011 & 0,0039 & 0,000 & 0,06 \\
\hline
\end{tabular}

Fonte: Elaboração própria. 
Figura 1 - Mapa de clusters - serviç̧os culturais

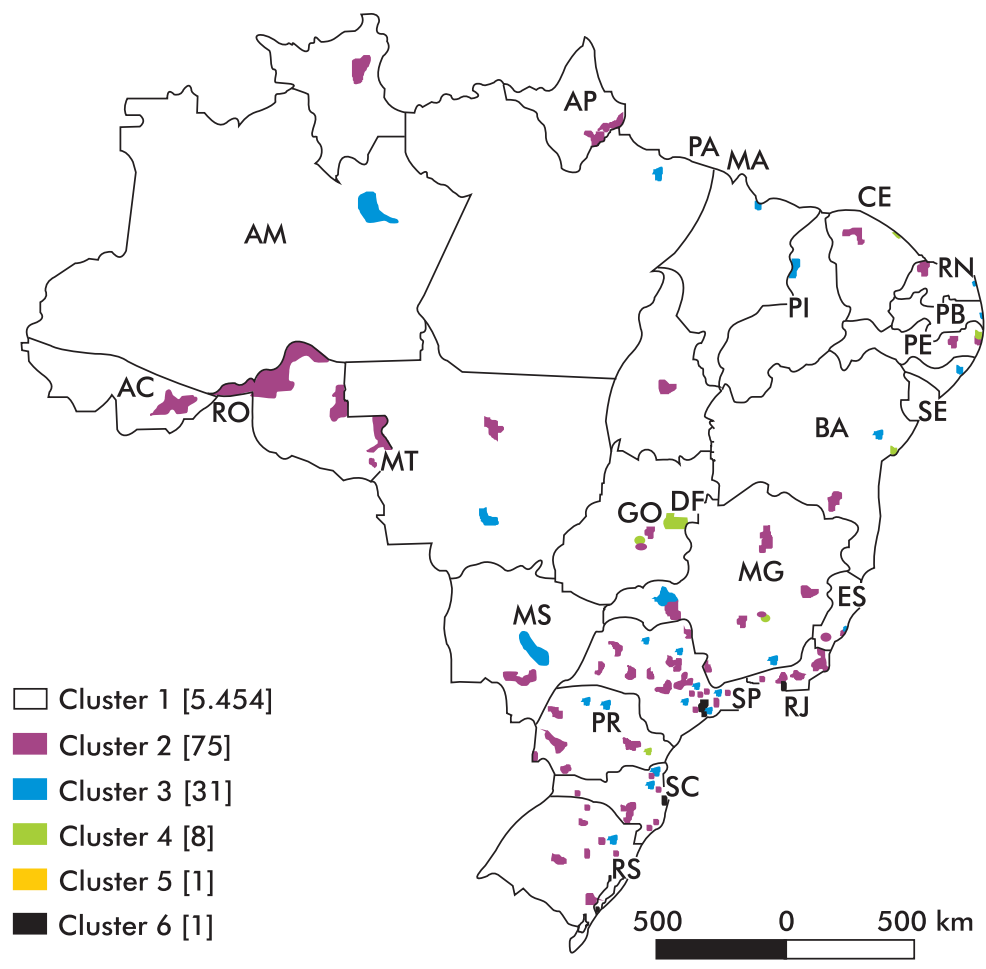

Fonte: Elaboração própria.

Os resultados sugerem a formação de seis clusters. Dois deles (5 e 6) são formados por apenas um município: Rio de Janeiro e São Paulo. Elas são as duas maiores cidades do Brasil e possuem muitas indústrias criativas, especialmente aquelas ligadas ao setor de audiovisual e publicidade, como destacado por Machado et al. (2013). São Paulo possui quantitativamente mais empregos e estabelecimentos culturais do que o Rio de Janeiro. Porém, o Rio de Janeiro tem mais estabelecimentos culturais para cada 10.000 habitantes. Esses dois clusters possuem a maior razão renda média obtida nos setores culturais em proporção ao rendimento médio dos trabalhadores, sendo que São Paulo apresenta leve superioridade nesta variável. O percentual de empregados nos setores culturais em proporção aos empregos totais é semelhante entre eles: cerca de 1\%.

O cluster 4 é composto por Belo Horizonte, Curitiba, Porto Alegre, Brasília, Fortaleza, Recife, Salvador e Goiânia. Esses municípios possuem características parecidas com Rio de Janeiro e São Paulo, porém, são razoavelmente inferiores em termos quantitativos. Possuem, em média, 2,2 estabelecimentos culturais para cada 10.000 habitan- 
tes, ao passo que Rio e São Paulo têm, respectivamente, 2,86 e 2,66. A renda média dos trabalhadores do setor cultural neste grupo é a metade daquela recebida pelos trabalhadores de São Paulo, sendo este, talvez, um elemento importante na diferenciação entre os clusters. Por outro lado, as oito cidades que compõem este grupo têm a maior participação relativa em empregados no setor de cultura dentre todos os demais grupos: $1,25 \%$.

O cluster 3 é formado por 31 cidades, sendo algumas capitais e outros municípios que formam importantes regiões metropolitanas do Brasil: Manaus, Belém, São Luís, Teresina, Natal, João Pessoa, Maceió, Aracaju, Feira de Santana, Juiz de Fora, Uberlândia, Vitória, Niterói, Barueri, Campinas, Guarulhos, Ribeirão Preto, Santo André, Santos, São Bernardo do Campo, São José do Rio Preto, São José dos Campos, Sorocaba, Londrina, Maringá, Blumenau, Florianópolis, Joinville, Caxias do Sul, Campo Grande e Cuiabá. Aqui, todas as variáveis são quantitativamente menores que aquelas observadas nos três grupos anteriores, porém, ainda estão acima da média brasileira. Esses municípios possuem, em média, menos de dois estabelecimentos culturais para cada 10.000 habitantes e pouco mais de $0,7 \%$ dos trabalhadores formais estão no setor cultural.

O que diferencia o cluster 2, formado por 75 municípios, do terceiro agrupamento, é o valor médio do número de estabelecimentos culturais para cada 10.000 habitantes. Aqui, este corresponde a 1,88 , ao passo que no quarto grupo é de 1,85 . Fora isso, os indicadores do cluster 2 são inferiores a todos os outros apresentados anteriormente. Contudo, eles ainda se mantêm acima da média nacional. Existem cerca de 40 estabelecimentos culturais em cada um desses 75 municípios, número bem abaixo dos 112 observados no quarto cluster. Na mesma direção, apenas pouco mais que 0,5\% dos trabalhadores formais estão empregados nos setores associados à cultura. Ademais, o rendimento médio de um trabalhador do setor cultural é cerca de três vezes menor nesse cluster do que em São Paulo.

É importante notar que os cinco grupos formados concentram apenas $2 \%$ dos municípios brasileiros. A extensa maioria dos municípios, 5.454, compõe o cluster 1, cujas características são as mais deficientes: essas cidades empregam cerca de 11 pessoas, em média, no setor cultural; possuem 0,5 estabelecimento cultural para cada 10.000 habitantes; apenas $0,1 \%$ dos seus trabalhadores formais estão no setor cultural; e a proporção entre a renda dos trabalhadores deste setor em relação à dos demais trabalhadores é a mais baixa dos grupos.

Os resultados demonstram que o setor cultural é muito concentrado espacialmente. Isso ocorre fundamentalmente nas capitais e municípios brasileiros que constituem regiões metropolitanas. Essa concentração espacial das atividades culturais já foi identificada em estudos anteriores (Scott, 2005; Cooke e Lazzeretti, 2008; Machado et al., 2013). 
É importante notar que, a despeito do menor número de variáveis utilizadas para a formação dos clusters, há um padrão semelhante àqueles observados em outros trabalhos, como o de Machado et al. (2013) e de Ribeiro et al. (2014). Isto é, as maiores cidades do Brasil, Rio de Janeiro e São Paulo, destoam das demais. De fato, o setor cultural é mais presente nesses municípios. Ademais, nota-se que a ampla maioria das cidades brasileiras possui um setor cultural quase que inexistente. Os grupos intermediários variam com o método de estimação, bem como as variáveis utilizadas.

No intuito de complementar a análise de conglomerados, apresentam-se a seguir os resultados do método shift-share, cujo objetivo é identificar as vantagens competitivas e de especialização (efeito alocação) do setor de serviços culturais das RME brasileiras, bem como classificá-los como dinâmicos ou estagnados no período 2006 a 2013. Ou seja, será que os clusters que apresentaram os melhores resultados $(2,3,4,5$ e 6) são formados por RME que, simultaneamente, aportam setores culturais competitivos, especializados e dinâmicos? Ou ainda, será que o cluster com pior desempenho (1) foi constituído por RME com setores culturais estagnados, não competitivos e não especializados?

Antes de responder a tais questionamentos, é importante salientar que a participação relativa do setor "serviços culturais" das 38 RME brasileiras ainda é pouco expressiva em termos de emprego ${ }^{3}$. Em 2006, sua participação correspondeu, em média, a apenas $0,82 \%$ dos empregos totais, ao passo que em 2013 esta participação caiu para $0,69 \%$. As cinco RME com maiores participações, em 2013, foram São Paulo (33,2\%), Rio de Janeiro (17,1\%), Porto Alegre (5,4\%), Curitiba (5,2\%) e Belo Horizonte $(5,1 \%)$.

O componente estrutural indica a quantidade de emprego que uma região ganha ou perde em virtude de sua composição setorial. Em outras palavras, este componente será positivo se a região abrigar predominantemente setores dinâmicos, caso contrário, será negativo. A comparação entre as taxas de crescimento do setor de serviços culturais nas RME brasileiras $\left(r_{i j}\right)$ e a taxa de crescimento total da região $\left(r_{i j}\right)$, durante o período 2006-2013, permite definir se o setor cultural naquela determinada RME é classificado como dinâmico ou estagnado. Se essa RME apresentar o $r_{i j}>r_{i j}$ para serviços culturais, dizemos que o setor é dinâmico naquela região; caso contrário, ou seja, $r_{i j}<r_{i j}$ o setor pode ser considerado estagnado no período em análise (Haddad, 1989). Os resultados são expressos na Tabela 5.

3 Variável utilizada para aplicação do shift-share. 
Tabela 5 - Serviços culturais dinâmicos ou estagnados na RME de origem

\begin{tabular}{|c|c|}
\hline Serviços Culturais Dinâmicos $\left(r_{i j}>r_{i j}\right)$ & Serviços Culturais Estagnados $\left(r_{i j}>r_{i j}\right)$ \\
\hline Belém & Macapá \\
\hline Grande São Luís & Natal \\
\hline Fortaleza & Recife \\
\hline Colar Metropolitano do Vale do Aço & Maceió \\
\hline Grande Vitória & Salvador \\
\hline Área de Expansão Metropolitana de Florianópolis & Belo Horizonte \\
\hline Núcleo Metropolitano do Norte/Nordeste Catarinense & Colar Metropolitano de Belo Horizonte \\
\hline Área de Expansão Metropolitana de Carbonífera & Vale do Aço \\
\hline Região Integrada de Desenv. da grande Teresina & Rio de Janeiro \\
\hline Região Administrativa Integrada do Desenv. do Pólo & São Paulo \\
\hline \multirow[t]{18}{*}{ Petrolina e Juazeiro } & Baixada Santista \\
\hline & Campinas \\
\hline & Curitiba \\
\hline & Londrina \\
\hline & Maringá \\
\hline & Núcleo Metropolitano de Florianópolis \\
\hline & Núcleo Metropolitano do Vale do Itajaí \\
\hline & Área de Expansão Metropolitana do Vale do Itajaí \\
\hline & $\begin{array}{l}\text { Área de Expansão Metropolitana do Norte/Nordeste } \\
\text { Catarinense }\end{array}$ \\
\hline & Núcleo Metropolitano de Foz do Rio Itajaí \\
\hline & Área de Expansão Metropolitana de Foz do Rio Itajaí \\
\hline & Núcleo Metropolitano de Carbonífera \\
\hline & Núcleo Metropolitano de Tubarão \\
\hline & Área de Expansão Metropolitana de Tubarão \\
\hline & Porto Alegre \\
\hline & Goiânia \\
\hline & João Pessoa \\
\hline & Região Integrada de desenv. do DF e entorno \\
\hline
\end{tabular}

Fonte: Elaboração própria a partir dos dados da RAIS.

Percebe-se que a maioria das RME brasileiras, 28 (74\%), teve o setor de serviços culturais considerado estagnado entre 2006 e 2013, já que $r_{\mathrm{ij}}<r_{\mathrm{jj} .}$ Nas outras $10 \mathrm{RME}$, o setor de serviços culturais pode ser considerado como dinâmico, pois $r_{\mathrm{ij}}>r_{\mathrm{j} j}$. É importante ressaltar que metade das RME que apresentaram os serviços culturais dinâmicos estão localizadas nas regiões Norte e Nordeste. Por outro lado, pela análise de conglomerados, percebeu-se que essas duas regiões apresentaram, na sua maioria, municípios com baixos níveis de emprego, renda e estabelecimentos no setor cultural, isto é, cluster 1. A princípio, este parece ser um resultado contraditório, porém, não o é. O que ocorre é que nas regiões mais desenvolvidas do país (Sul e Sudeste) a indústria e outros tipos de serviços têm uma maior importância relativa, o que não acontece nas regiões brasileiras menos desenvolvidas. 
O componente diferencial, por sua vez, indica a quantidade de emprego que a RME $j$ ganhou ou perdeu em função da taxa de crescimento do emprego de determinados setores $\left(r_{i j}\right)$ ser diferente da taxa de todas as regiões $\left(r_{i t}\right)$. Desse modo, caso $r_{i j}>$ $r_{i t}$, houve um movimento de especialização, evidenciando que o setor $i$ da $\operatorname{RME~} j$ cresceu mais que o mesmo setor no total das regiões. Assim, se conseguir atrair um número crescente de firmas, determinada RME pode crescer mais rapidamente que outras. Por outro lado, se $r_{i j}<r_{i t}$, houve uma perda de competitividade do setor $i$ da RME j. Segundo Haddad (1989), as razões destes movimentos são de natureza locacional como, por exemplo: incentivos fiscais, diferenças de preços relativos de insumos entre regiões, variações nos custos de transporte etc. A Tabela 6 indica os resultados do efeito alocação para o período 2006 a 2013, de acordo com as RME brasileiras.

Tabela 6 - Tipologia do efeito alocação do setor serviços culturais

\begin{tabular}{lclc}
\hline \multicolumn{1}{c}{ Região Metropolitana } & Cod & Cod \\
\hline Belém & 2 & Maringá & 2 \\
Macapá & 2 & Núcleo Metropolitano de Florianópolis & 2 \\
Grande São Luís & 2 & Área de Expansão Metropolitana de Florianópolis & 2 \\
Fortaleza & 2 & Núcleo Metropolitano do Vale do Itajaí & 4 \\
Natal & 4 & Área de Expansão Metropolitana do Vale do Itajaí & 2 \\
Recife & 2 & Núcleo Metropolitano do Norte/Nordeste Catarinense & 2 \\
Maceió & 4 & Área de Expansão Metropolitana do Norte/Nordeste Catarinense & 4 \\
Salvador & 2 & Núcleo Metropolitano de Foz do Rio Itajaí & 4 \\
Belo Horizonte & 4 & Área de Expansão Metropolitana de Foz do Rio Itajaí & 3 \\
Colar Metropolitano de Belo Horizonte & 2 & Núcleo Metropolitano de Carbonífera & 3 \\
Vale do Aço & 4 & Área de Expansão Metropolitana de Carbonífera & 2 \\
Colar Metropolitano do Vale do Aço & 2 & Núcleo Metropolitano de Tubarão & 2 \\
Grande Vitória & 2 & Área de Expansão Metropolitana de Tubarão \\
Rio de Janeiro & 3 & Porto Alegre & 2 \\
São Paulo & 3 & Goiânia \\
Baixada Santista & 2 & João pessoa \\
Campinas & 2 & Região Integrada de Desenv. do DF e entorno \\
Curitiba & 1 & Região Integrada de Desenv. da Grande Teresina \\
Londrina & 1 & Região Administrativa Integrada do Desenv. do Pólo Petrolina e & 3 \\
& & Juazeiro & 2 \\
\hline
\end{tabular}

Nota: 1 - Vantagem competitiva, especializada; 2 - vantagem competitiva, não especializada; 3 - desvantagem competitiva, especializada; 4 - desvantagem competitiva, não especializada.

Fonte: Elaboração própria a partir dos dados da RAIS.

O setor "serviços culturais", em 61\% das RME brasileiras, entre 2006 e 2013, pode ser caracterizado como uma atividade que apresentou vantagens competitivas em relação a outros segmentos econômicos, entretanto, não teve movimentos de especialização. Ademais, para 21\% das RME, o segmento cultural, naquela localidade, não foi competitivo nem especializado. Por outro lado, apenas em duas RME (5\%) o setor de serviços culturais foi simultaneamente competitivo e especializado: Curitiba e Lon- 
drina. Vale destacar que ambas as RME estão localizadas na região Sul do país, evidenciando uma importância relativa dessa região no que se refere ao setor serviços culturais. Isso também pode ser corroborado pela análise de cluster, já que a maior parte dos municípios que constituem essas RME localizou-se no grupo 3.

Além disso, apesar de cinco RME (13\%) terem apresentado os serviços culturais considerados especializados durante o período em análise, eles não foram competitivos em face de outros setores de atividade econômica. Entre essas regiões, encontram-se três importantes RME do país: Rio de Janeiro, São Paulo e Porto Alegre. Além disso, os principais municípios que constituem essas RME fizeram parte dos clusters em que os serviços culturais apresentaram mais empregos, melhor remuneração e um maior número relativo de estabelecimentos culturais.

A Tabela 7 apresenta as tipologias resultantes do método diferencial-estrutural para as regiões e o setor em estudo. Vale salientar que o resultado da Tabela 7 é decorrente da equação 3, proposta por Esteban-Marquillas (1972). Dessa forma, a VLT é resultante da combinação da Variação Estrutural (E), do Efeito Competitivo (C) e do Efeito Alocação (A), isto é, dos componentes de especialização e de vantagem competitiva. Assim, a VLT indicará quais RME cresceram mais (dinâmicas) e quais cresceram menos (não dinâmicas ou estagnadas) que a média global (soma de todas as RME). A Variação Estrutural revela que uma RME ganhou (perdeu) empregos em função de estar especializada em setores dinâmicos (não dinâmicos). O Efeito Competitivo indica o nível de especialização do emprego nas RME. O Efeito Alocação, por fim, acusa se o crescimento regional pode ocorrer em razão da RME apresentar e combinar suas vantagens competitivas com sua especialização (Betarelli e Simões, 2011).

A partir disso, foi possível elaborar, para o setor serviços culturais, as tipologias de acordo com as RME brasileiras para o período de 2006 a 2013. Essas tipologias nos fornecem 14 combinações possíveis (sete para VLT positivo e sete para VLT negativo). Contudo, só são apresentadas na Tabela 7 as combinações que apareceram na nossa análise.

Do total das RME, 28 (74\%) apresentaram VLT negativa, o que significa que essas regiões perderam empregos líquidos no setor de serviços culturais no período em análise. No sentido oposto, 10 (26\%) RME ganharam empregos líquidos interperíodos.

Os resultados do grupo A5 indicam que 10 (26\%) RME, apesar de apresentarem efeitos alocativos (A) e estruturais (E) negativos, exibiram um setor cultural/criativo competitivo (C) no período entre 2006 e 2013. Esse resultado contribuiu para uma VLT positiva. A mão de obra qualificada e especializada, a infraestrutura econômica e um amplo mercado consumidor são fatores que contribuem positivamente para a competitividade do segmento. 
Tabela 7 - Tipologias dos serviços culturais das RME brasileiras pelo método shift-share (2006-2013)

\begin{tabular}{|c|c|c|c|}
\hline Cod & $\begin{array}{c}\text { VLT } \\
\text { (sinal) }\end{array}$ & Tipologia & Regiões Metropolitanas \\
\hline A5 & + & $\begin{array}{l}\text { C positiva supera } \\
\text { E e A negativa }\end{array}$ & $\begin{array}{l}\text { Belém; Grande São Luís; Fortaleza; Colar Metropolitano do Vale do Aço; } \\
\text { Grande Vitória; Área de Expansão Metropolitana de Florianópolis; Núcleo } \\
\text { Metropolitano do Norte/Nordeste Catarinense; Área de Expansão } \\
\text { Metropolitana de Carbonífera; Região Integrada de Desenvolvimento da } \\
\text { Grande Teresina; Região Administrativa Integrada do Desenvolvimento do } \\
\text { Polo Petrolina e Juazeiro }\end{array}$ \\
\hline B1 & - & E, C, A negativas & $\begin{array}{l}\text { Rio de Janeiro; São Paulo; Área de Expansão Metropolitana de Foz do Rio } \\
\text { Itajaí; Núcleo Metropolitano de Carbonífera; Porto Alegre }\end{array}$ \\
\hline B3 & - & $\begin{array}{l}\text { E e A negativas } \\
\text { superam } C \text { positiva }\end{array}$ & $\begin{array}{l}\text { Macapá; Recife; Salvador; Colar Metropolitano de Belo Horizonte; Baixada } \\
\text { Santista; Campinas; Maringá; Núcleo Metropolitano de Florianópolis; Área } \\
\text { de Expansão Metropolitana do Vale do Itajaí; Núcleo Metropolitano de } \\
\text { Tubarão; Área de Expansão Metropolitana de Turbarão; João Pessoa; Região } \\
\text { Integrada de Desenvolvimento do DF e Entorno }\end{array}$ \\
\hline B4 & - & $\begin{array}{l}\text { E e C negativas } \\
\text { superam A positiva }\end{array}$ & $\begin{array}{l}\text { Natal; Maceió; Belo Horizonte; Vale do Aço; Núcleo Metropolitano do Vale } \\
\text { do Itajaí; Área de Expansão Metropolitana do Norte/Nordeste Catarinense; } \\
\text { Núcleo Metropolitano de Foz do Rio Itajaí; Goiânia }\end{array}$ \\
\hline B7 & - & $\begin{array}{l}\text { E negativa supera } \\
\text { C e A positiva }\end{array}$ & Curitiba; Londrina \\
\hline
\end{tabular}

Fonte: Elaboração própria a partir dos dados da RAIS.

O grupo B1 indica que cinco (13\%) RME apresentaram todos os efeitos (Alocação, Estrutural e Competitivo) negativos, o que implicou necessariamente uma VLT negativa. Os resultados do grupo B3 indicam que em 13 (34\%) RME o efeito competitivo (C) positivo foi superado pelos efeitos estrutural e alocação negativos. Para o grupo B4, formado por oito (21\%) RME, o efeito alocação foi positivo, no entanto, efeito alocação negativo unido com um setor serviços culturais não dinâmico resultou numa VLT negativa. Por fim, o grupo B7 revela que dois (5\%) RME (Curitiba e Londrina) apresentaram os efeitos competitivo e alocação positivos, mas que foram superados pelo efeito estrutural negativo.

\section{CONSIDERAÇÕES FINAIS}

Conforme exposto ao longo deste trabalho, o setor cultural e artístico tem sido objeto de estudo de parte dos economistas. Os eventos artísticos podem atrair visitantes aos centros urbanos e, por conseguinte, produzir efeitos expansivos na renda local. Ademais, produtos relacionados à arte e à cultura têm representatividade considerável na balança comercial de alguns países. O desenvolvimento do setor cultural pode, ainda, contribuir para a atração de indivíduos criativos, os quais são mais qualificados e, portanto, mais produtivos. Tendo em vista que a economia da cultura ganhou espaço 
no meio acadêmico, a proposta desse artigo foi tentar identificar algumas características desse setor nos municípios e regiões metropolitanas brasileiras. Entende-se que o desenvolvimento futuro de políticas regionais associado à economia da cultura exige, num primeiro momento, a caracterização deste setor do ponto de vista regional. Para tanto, por meio da análise de conglomerados, identificaram-se grupos de municípios com características similares entre si a partir da utilização de dados de empregos formais, renda média e número de estabelecimentos associados às atividades culturais em cada unidade de análise.

Os resultados indicam a existência de seis clusters. Os grupos 5 e 6 foram formados por apenas um município cada: Rio de Janeiro e São Paulo. Este último possui quantitativamente mais empregos e estabelecimentos culturais do que o Rio de Janeiro. Esses dois clusters possuem a maior razão renda média - obtida nos setores culturais - em proporção ao rendimento médio dos trabalhadores. O cluster 4 é composto por Belo Horizonte, Curitiba, Porto Alegre, Brasília, Fortaleza, Recife, Salvador e Goiânia. Esses municípios possuem números razoavelmente inferiores, em termos quantitativos, aos números de São Paulo e Rio de Janeiro. O cluster 3 é formado por 31 cidades, sendo algumas delas capitais e, outras, municípios de importantes regiões metropolitanas do Brasil. Esses municípios possuem, em média, menos de dois estabelecimentos culturais para cada 10.000 habitantes, e pouco mais de $0,7 \%$ dos trabalhadores formais estão no setor cultural. O cluster 2 é formado por 75 municípios, cujos indicadores são inferiores a todos os outros apresentados anteriormente, mas se mantêm acima da média nacional. Esses cinco primeiros grupos concentram apenas $2 \%$ dos municípios estudados. A extensa maioria dos municípios, 5.454, compõe o cluster 1, cujas características são as mais deficientes: esses municípios empregam poucas pessoas, em média, no setor cultural; possuem 0,5 estabelecimento cultural para cada 10.000 habitantes; apenas $0,1 \%$ dos seus trabalhadores formais estão no setor cultural; e a proporção entre a renda dos trabalhadores desse setor em relação à dos demais trabalhadores é a mais baixa dos grupos.

No intuito de complementar a análise de conglomerados, optou-se pela realização do método shift-share, cujo objetivo foi captar as vantagens competitivas e especialização do setor, bem como classificá-los como dinâmicos ou estagnados no período de 2006 a 2013. Foi possível notar que a participação do setor serviços culturais nas 38 RME brasileiras ainda é pouco expressiva em termos de emprego. Notou-se ainda que $74 \%$ das RME brasileiras tiveram o setor serviços culturais considerado como estagnado entre 2006 e 2013. Merece destaque o fato de que apenas em duas RME o setor serviços culturais foi simultaneamente competitivo e especializado, quais sejam: Curitiba e Londrina. Isso também pode ser corroborado pela análise de cluster, já que os principais municípios que constituem essas RME localizaram-se no cluster 3. 
Ao que parece, qualquer política pública voltada ao desenvolvimento do setor cultural encontrará três importantes desafios: i) a concentração do setor, que praticamente está restrito aos municípios metropolitanos; ii) o fraco desempenho dos municípios do Norte e Nordeste; iii) a renda dos trabalhadores desse setor, que parece estar acima da média apenas nos municípios de São Paulo e Rio de Janeiro.

Vale salientar ainda que os resultados apresentados devem ser vistos com cautela, já que a utilização dos dados da RAIS, como já mencionado ao longo do texto, constitui uma limitação devida à contabilização somente dos empregos formais e dos estabelecimentos com mais de cinco empregados registrados. Nesse sentido, a utilização de dados dos últimos censos demográficos, bem como diferentes classificações setoriais, pode enriquecer e fazer avançar a discussão.

\section{REFERÊNCIAS}

BETARELLI, A. A.; SIMÕES, R. F. A dinâmica setorial e os determinantes locacionais das microrregiões paulistas. Economia Aplicada, v. 15, n. 4, 2011.

BILLE, T.; SCHULZE, G. G. Culture in urban and regional development. In: GINSBURGH, V. A. e THROSBY, D. (Orgs.) Handbook of the Economics of Arts and Culture. North-Holland, 2006.

COOKE, P.; LAZZERETTI, L. Creative cities, cultural clusters and local economic development. Cheltenham: Edward Elgar, 2008.

DINIZ, S. C; MACHADO, A. F. Consumo de bens e serviços culturais nas metrópoles brasileiras - uma análise a partir de dados da POF. Políticas Culturais em Revista, n. 2, p. 62-79, 2009.

DINIZ, S. C.; MACHADO, A. F. Analysis of the consumption of artistic-cultural goods and services in Brazil. Journal of Cultural Economics, v. 35, 2011.

ESTEBAN-MAQUILLAS J. M. Shift and share analysis revisited. Regional and Urban Economics. North-Holland, v. 2, n. 3, 1972.

FÁVERO, L. P.; BELFIORE, P., SILVA, F. L., CHAN, B. L. Análise de dados: modelagem multivariada para tomada de decisões. Rio de Janeiro: Elsevier, 2009.

FLORIDA, R. The rise of the creative class - and how it's transforming work, leisure, community and everyday life. New York: Basic Books, 2002.

FORMAN, A. K. Die latent-class-analyse: Einführung in die Theorie und Anwendung. Weinheim: Beltz, 1984.

GOLGHER, A. B. As cidades e a classe criativa no Brasil: diferenças espaciais na distribuição de indivíduos qualificados. Revista Brasileira de Estudos da População, v. 25, p. 109-129, 2008.

GOLGHER, A. B. A distribuição de indivíduos qualificados nas regiões metropolitanas brasileiras: a influência do entretenimento e da diversidade populacional. Nova Economia, v. 21, n. 1, p. 109-134, 2011. 
GOUVÊA, M. A.; LA PLATA, J. P. F. Segmentos de médicos para a categoria de produtos cirúrgicos no Brasil: In: Seminário em Administração FEA-USP, 9, São Paulo, SP, 2006.

HADDAD, P. R. (Org.) Economia regional, teorias e métodos de análise. Fortaleza: BNB/ ETENE, 1989.

HAIR JR., F. F.; ANDERSON, R. E.; TATHAN, R. L.; BLACK, W. C. Análise multivariada de dados. 5 ed. Porto Alegre: Bookman, 2005.

JACOBS, J. Morte e vida das grandes cidades. São Paulo: Matins Fontes, 2001.

KOTKIN, J. The new geography: how the digital revolution is reshaping the American landscape. New York: Random House, 2000.

MACHADO, A. F.; SIMÕES, R., DINIZ, S. C. Urban amenities and the development of creative clusters: the case of Brazil. Current Urban Studies, v. 1, p. 92-101, 2013.

MARKUSEN, A. Cultural planning and the creative city. Ft. Worth, TX: American Collegiate Schools of Planning meetings, 2006.

MARKUSEN, A. A consumption base theory of development: an application to the rural cultural economy. Agricultural and Resource Economics Review, v. 36, n. 1, 2007.

MARKUSEN, A.; SCHROCK, G. The artistic dividend: urban artistic specialization and economic development implications. Urban Studies, v. 43, n. 10, 2005.

MAROCO, J. Análise estatística com utilização do SPSS. 3 ed. Lisboa: Edições Síbano, 2007.

MARSHALL, A. Princípios de economia. São Paulo: Nova Cultural, 1984.

PAGLIOTO, B. F.; MACHADO, A. F. Perfil dos frequentadores de atividades culturais: o caso nas metrópoles brasileiras. Estudos Econômicos, v. 42, n. 4, p. 701-730, 2012.

RIBEIRO, L. C. S. ET AL. Distribuição espacial da indústria do lazer no Brasil. Texto para Discussão, UFMG/CEDEPLAR, n. 507, 2014.

SANTAGATA, W. "Cultural districts and their role in developed and developing countries". In: GINSBURGH, V. A.; THROSBY, D. (Orgs.) Handbook of the Economics of Arts and Culture. North-Holland, 2006.

SCANLON, R.; LONGLEY, R. "The arts as an industry: their economic importance to the New York-New Jersey metropolitan region”. In: HENDON, W. S.; GRANT, N. K.; SHAW, D. V. (Eds.) The Economics of Cultural Industries. Association for Cultural Economics, University of Akron, 1984.

SCOTT, A. A perspective of economic geography. Journal of Economic Geography, v. 4, p. 479-499, 2004.

SCOTT, A. J. On Hollywood. The place, the industry. Princeton, NJ: Princeton University Press, 2005.

SOMMERS, P.; CARLSON, D. The new economy in metropolitan Seattle: High tech firm location decisions within the metropolitan landscape. Report for the Brookings Institution Center on Urban and Metropolitan Affairs, Washington, DC, 2000.

WAITT, G.; GIBSON, C. Creative small cities: rethinking the creative economy in place. Urban Studies, 46, n. 5-6, p. 1223-1246, 2009. 